\title{
Authoritarian Predispositions and Attitudes towards Redistribution
}

\author{
Gizem Arikan (Corresponding author) \\ Department of Political Science \\ Trinity College Dublin \\ 2-3 College Green \\ Dublin 2, Ireland \\ Phone: (353) - 1- 8961100 \\ E-mail: arikang@tcd.ie \\ Eser Sekercioglu \\ Department of Political Science and International Relations \\ Izmir University of Economics \\ 35330 Balcova, Izmir, Turkey \\ E-mail: eser.sekercioglu @gmail.com
}

\section{Forthcoming in Political Psychology.}

Acknowledgements: For invaluable feedback and support at different stages of this project we are grateful to Ali Carkoglu, Albert Falco-Gimeno, Stanley Feldman, PJ Henry, Howard Lavine, Rebecca Morton, Jordi Munoz, Harald Schoen, two anonymous reviewers and the journal's editor as well as the participants of POLEXP, MZES and NYUAD seminar series and ESPA workshop. The study was supported by grants from Young Scientist Award Program of the Turkish Academy of Sciences (TUBA-GEBIP 2015-18) and Science Academy Young Scientist Awards Program (BAGEP 2016) (first author). Any errors or omissions are, of course, our own. 


\begin{abstract}
Authoritarian predispositions are associated with a preference for order, certainty and security. Using data from European Social Surveys (ESS), we show that this association extends to attitudes towards redistributive policies. We demonstrate that support for redistributive policies that emphasize the government's responsibility to provide old age, health and unemployment benefits are positively associated with authoritarian predispositions. We also provide evidence that perceived economic threats moderate this relationship such that, for individuals who perceive higher levels of economic threat, the relationship between authoritarian predispositions and support for government responsibility is stronger. These results show that authoritarian predispositions are not only associated with social preferences but also attitudes towards economic policies.
\end{abstract}

Keywords: Authoritarianism, redistribution, ideology, threat, values 


\section{Introduction}

Are authoritarian predispositions positively associated with support for redistributive policies? For many years, students of authoritarianism would not consider this a pertinent question. While researchers found convincing evidence for authoritarianism's relationship with conservative social preferences, prejudice, and intolerance, little effort was spent to extend the same line of inquiry into the relationship between authoritarianism and economic attitudes. Authoritarian predispositions are associated with a preference for order, conformity, and security over freedom, autonomy, and change (Duckitt, 2001; Feldman, 2003; Stenner, 2005, 2009). Therefore, it is not surprising to expect a positive association between them and socially conservative preferences that aim at upholding the status quo and avoiding uncertainty (Jost et al., 2003). Using the same line of reasoning, one might expect authoritarian orientations to be associated with support redistributive policies that decrease economic uncertainty and help maintain social order and security. However, few researchers have tackled this apparent puzzle and those who did produced conflicting findings. While some studies report no significant relationship between authoritarianism and economic attitudes (Cizmar et al., 2014; Feldman \& Johnston, 2014), others have found substantial numbers of voters with economically liberal and socially conservative tendencies (Lefkofridi, Wagner, \& Willmann, 2014; Van der Brug \& van Spanje, 2009). In even more nuanced treatments of the subject, researchers have demonstrated that the effect of authoritarianism on economic attitudes depends on political engagement (Johnston, Lavine, \& Federico, 2017) and that economic conservatism is not always associated with social conservatism (Cochrane, 2010; Federico \& Malka 2018; Malka, Lelkes, \& Soto, 2017). 
While these recent studies are a crucial step towards unraveling the relationship between authoritarian orientations and economic attitudes, important gaps in our understanding relationship remain. First, most direct tests of the relationship between authoritarianism and redistributive preferences are confined to the U.S., which is considered to be exceptional in many aspects. ${ }^{1}$ Using cross-national survey data, we show that higher levels of authoritarian predispositions are positively associated with support for greater government responsibility in providing health, old age and unemployment benefits in the European context. Second, existing studies largely ignore the dynamic way that authoritarian predispositions interact with the sociopolitical context and especially the role of threat perceptions. Recent formulations of the concept show that we should take threat perception into account in explaining the relationship between these predispositions and political attitudes (Feldman \& Stenner, 1997; Feldman, 2003; Hetherington \& Weiler 2009; Stenner, 2005). We show that the positive relationship between authoritarian predispositions and support for redistribution is stronger in the presence of economic threat.

\section{Authoritarianism: A conceptual and methodological labyrinth}

Research on authoritarianism has a long and sometimes confusing history, making it hard to define and operationalize the concept. Over time, both the conceptualization and measurement of authoritarian orientations have changed. The concept and first measure (F-scale) were

\footnotetext{
${ }^{1}$ The small size of its welfare state and values stressing self-reliance and economic individualism are suggested to set the United States apart from other developed democracies in terms of the predispositions affecting attitudes towards redistribution (Lipset, 1997). More recently, Federico, Johnston, \& Lavine (2017) argued that partisan polarization has made identity expression a salient motivation, especially for politically engaged Americans, which also affects the way psychological predispositions relate to support for redistribution.
} 
developed to explain the rise of Fascism and Nazism in Europe (Adorno et al., 1950). However, both the psychodynamic approach and the F-scale itself has been subject to numerous criticisms (See, for example, Altemeyer, 1981; Duckitt, 1992; Feldman, 2003). To overcome the limitations of the psychoanalytic conceptualization and the F-scale, Altemeyer $(1981,1996)$ remodeled authoritarianism as an attitudinal complex acquired through political socialization. While Altemeyer's social learning approach had wider empirical application, and the resulting rightwing authoritarianism (RWA) scale yielded more robust measurements, the approach did not necessarily provide much theoretical improvement or conceptual clarity (Feldman, 2003: 43). The RWA scale was also criticized as reflecting ideological beliefs rather than describing psychological dispositions (Duckitt, 2001; Feldman \& Stenner, 1997; Feldman, 2003).

More recent studies tend to treat authoritarianism neither as a personality trait nor as a stable set of attitudes but as manifestations of predispositions towards autonomy and authority (Cohrs et al., 2005; Duckitt, 1992, 2001; Feldman \& Stenner, 1997; Feldman, 2003; Stenner, 2005). According to this approach authoritarian predispositions reflect an appropriate balance between group authority and uniformity on the one hand and individual autonomy and diversity on the other (Duckitt, 1989: 72). In addition to providing a new theoretical basis for authoritarianism, this approach also allows for a dynamic relationship between authoritarian predispositions and exclusionary and punitive attitudes, including prejudice and intolerance towards out-groups. Authoritarian predispositions act on attitudes and behavior more strongly when the individual perceives a threat to the status quo and feels insecure. The key insight is that during periods of relative safety, security, and general well-being the normative order is not threatened and the balance between authority and autonomy does not create much tension. However, when the normative order is threatened through rapid social change, political or 
economic crises, or other exogenous means authoritarian predispositions become activated and exert a greater effect on attitudes and behavior (Duckitt, 1989, 1992; Feldman, 2003; Feldman \& Stenner, 1997; Hetherington \& Weiler, 2009; Stenner, 2005). In fact, research into the role of threat in triggering exclusionary and intolerant attitudes has a long history, even predating the original studies on authoritarianism (see for example, Davies, 1962; Reich, 1946). This new conceptualization has been more successful in accounting for temporal and cross-cultural variations in levels of intolerance and punitive attitudes. This dynamic approach is the one we adopt in this study.

\section{Existing studies}

Redistributive policies are designed to reduce risk and uncertainty, provide a safety net and guard against the adverse societal consequences of economic downturns (Esping-Andersen, 1990). Government funded social programs are often framed by conservative political elites as a means to social stability and safety (King \& Ross, 2010). Thus, we might expect those with authoritarian predispositions to support redistributive policies because security and certainty brought about by redistributive policies are supportive of their values. While this reasoning is quite straightforward, evidence have been mixed and mostly limited to the U.S. Within the American context, empirical evidence has generally revealed either no association (Cizmar et al., 2014; Feldman \& Johnston, 2014) or a negative association (Ellis \& Stimson, 2012; Treier \& Hillygus, 2009) between authoritarianism and support for redistribution. Recently, however, Johnston, Lavine, \& Federico (2017) provide a partial solution to this puzzle by showing that this relationship depends on political engagement. They show that unengaged citizens who value security and certainty tend to hold socially conservative and economically liberal political 
preferences as both positions offer more certainty and stability. However, ideological cues formulated by the political elite in the United States counteract this leaning, such that for highly engaged individuals expressive influences overcome (or reorient) the dispositional influences. Thus, more engaged individuals with authoritarian predispositions identify with the Republican Party and its ideological package due to their cultural affinity and are therefore more likely to oppose redistributive policies. Thus, the political elite in the U.S. has "created a context in which economic opinion is increasingly a means by which engaged citizens signal their allegiance to a cultural in-group" (Johnston, Lavine, \& Federico, 2017: 45).

Yet, the findings of Johnston, Lavine, \& Federico (2017) are restricted to the U.S. context. Outside the U.S., there is evidence suggesting that there may be a direct relationship between authoritarian predispositions and support for redistribution. For example, surveys of Latin American political elites showed a positive association between authoritarian predispositions and preferences for an active, paternalistic government (Stevens, Bishin, \& Barr, 2006). In Turkey, tradition and conformity values were found to enhance government provision of social safety nets (Arikan, 2013). Using data from the World Values Survey (WVS) from 59 countries, Stenner (2009) found a negative relationship between authoritarianism and laissez-faire capitalism. Similarly, Malka and his colleagues found that security and certainty values were negatively associated with support for small government (Malka et al., 2015; Malka, Lelkes, \& Soto, 2017). Arikan \& Ben-Nun Bloom (2015) showed that individuals in societies that emphasize values of order, respect for tradition, security and obedience over individual autonomy were more likely to support government responsibility to provide social services. Still, these cross-national studies only provide indirect evidence of the relationship between authoritarian orientations and support for redistribution. 
In addition, they do not consider the dynamic nature of authoritarian predispositions and the potential moderating role of threat perceptions. Below, we lay out our expectations and reasoning for a positive association for authoritarian orientations and support for redistributive policies and the moderating effect of threat perceptions.

\section{Authoritarian predispositions, perceived threat, and support for redistribution}

Redistribution involves a complex set of policies and practices. Redistributive policies are designed both to act as a safety net for citizens during times of hardship and to promote social justice via decreasing economic inequality (Dryzek \& Goodin, 1986; Esping-Andersen, 1990). The dual nature of welfare states is reflected in the wide range of policies devised to answer these needs. While some policies are aim at enhancing the social security of the individual recipient targeting a specific domain (e.g. old age benefits), others are broader in scope and aim (e.g. progressive taxation).

We argue that attitudes towards policies that highlight government responsibility, and signal or imply increasing certainty and security will be positively related to authoritarian predispositions. These policies imply threat reduction and increased material security, and thus are more readily paired with individual needs for certainty and security. For example, unemployment benefits, healthcare benefits, and support for the elderly offer tangible relief to economic hardship and an element of safety and stability. On the other hand, policy debates about whether governments should increase or decrease spending offer no immediate links to the tangible elements of economic risk.

Hypothesis 1: Authoritarian predispositions are associated with higher levels of support for redistributive policies that emphasize government responsibility. 
As discussed above, a key element in the dynamic model of authoritarianism is the role of threat perception. According to the theory, authoritarian predispositions are best modeled as latent traits that are variably activated depending on socio-political context and individual's perceptions of it. In other words, the effect of authoritarian predispositions on attitudes and behavior is generally moderated by the socio-political environment. The most relevant aspect of the environment that triggers authoritarian responses is perceived threat (Feldman, 2003; Stenner, 2005). Evidence for this follows from the observation that support for exclusionary policies and punitive sentiments fluctuate quite drastically over time while the distribution of psychological tendencies in a given society does not. The intervening factor is found to be perceived (or actual) threat (Stenner, 2005).

Past research has shown that high levels of perceived threat leads to higher levels of punitive sentiments and intolerance for marginal groups (Doty, Peterson, \& Winter, 1991; Hetherington \& Weiler, 2009; Feldman, 2003; Rickert, 1998; Sales, 1973). The primary reason for this interaction between authoritarian predispositions and threat perception is the relative priority that authoritarians give to conformity over autonomy and their desire for social order. When individuals feel threatened their need for security and order increases at the expense of autonomy and tolerance for difference. In effect, threat perception acts as a catalyst in the process that activates authoritarian predispositions and increases their weight in shaping responses to social and political stimuli. We expect a similar process to work in the evaluation of redistributive policy proposals.

During periods when individuals fear that economic problems might undermine social order and cohesion, we may expect authoritarian tendencies to become more influential in guiding these attitudes. In other words, when perceived economic threat increases, we expect 
stronger support for social welfare policy proposals among those with stronger authoritarian tendencies.

Hypothesis 2: Perceived economic threat strengthens the positive relationship between authoritarian predispositions and support for redistributive policies that emphasize government responsibility.

\section{Data, variables and operationalization}

Our data comes from Round 4 of the European Social Surveys (ESS), collected in 2008 and 2009. This is the only large-scale cross-national survey that includes both a large battery of questions on redistributive preferences and the Schwartz Portrait Value Questionnaire (PVQ), which is widely used in measuring authoritarian predispositions (Cohrs et al., 2005; Duriez \& van Hiel, 2002; Feldman, 2003) as well as items that can be used as alternative measures of authoritarianism. ${ }^{2}$ The timing of this particular wave of the ESS corresponds to the global financial crisis so results may partly reflect this context. To provide a robust test of the hypotheses, we also use data from Round 8 of the ESS, which was conducted in 2016 and 2017. This is the second round of the ESS that includes a large battery of questions on attitudes towards redistribution. However this wave excludes items that could be used as measures of personal

\footnotetext{
${ }^{2}$ The World Values Survey (WVS) is another cross-national survey that has a shortened version of the Schwartz PVQ along with child rearing values, which is another widely used indicator of authoritarian predispositions (Federico, Fisher,\& Deason, 2011; Hetherington \& Weiler, 2009; Johnston, Lavine, and Federico 2017; Stenner 2005). However, WVS only includes one survey item about individual preferences for government responsibility, which does not make references to any specific policy. In addition, the WVS is limited with regards to the items tapping economic threat perceptions and social class positions of respondents.
} 
economic threat and as alternative measures for authoritarianism. For these reasons, we only use Round 8 to assess the robustness of the findings presented here.

We use three items that tap individual attitudes towards government responsibility to provide for those in need. The respondents were asked, on a scale that ranges from 0 to 10 , the extent to which they prefer government responsibility in different areas of social services: standard of living for the elderly, health care for the sick and standard of living for the unemployed. All dependent variables are recoded to vary between 0 and 1 , such that higher scores represent greater support for government responsibility.

Authoritarianism is measured using the PVQ available in the ESS. Schwartz's motivational theory of human values and the PVQ items measuring these values can be readily integrated with the conceptualization of authoritarianism as a preference for social order and security at the expense of individual autonomy (Cohrs, et al., 2005; Duriez \& van Hiel, 2002; Feldman, 2003). Schwartz has identified ten universal individual-level value orientations that form two higher-order dimensions that represent two fundamental conflicts in societies: openness to change versus conservation and self-transcendence versus self-enhancement (Schwartz, 1992). The first higher-order value dimension contrasts the motivational goals of tradition, conformity and security with values representing a preference for individual autonomy: self-direction, stimulation and hedonism. Authoritarian predispositions correspond to the first higher-order dimension. In fact, different measures of authoritarianism, including Altemeyer's RWA, correlate strongly with Schwartz's openness versus conservation dimension (Altemeyer, 1998; Cohrs et al., 2005; Duriez \& van Hiel, 2002; see also Feldman, 2003). The items are coded according to the instructions provided by the ESS. ${ }^{3}$ Since the authoritarian predisposition is defined as the relative

\footnotetext{
${ }^{3}$ For details, see http://www.europeansocialsurvey.org/docs/methodology/ESS1_human_values_scale.pdf.
} 
priority attached to conformity over autonomy, an individual's authoritarian predisposition is captured by subtracting her score on openness values from their score on conservation values (see, for example, Feldman, 2003).

Some scholars prefer to use childrearing values as indicators of orientation towards obedience and conformity to group norms (Federico, Fisher, \& Deason, 2011; Hetherington \& Suhay, 2011; Hetherington \& Weiler, 2009; Johnston, Lavine, \& Federico, 2017; Stenner, 2005). Unfortunately, the ESS does not include questions on childrearing values that allow us to construct a reliable measure of authoritarian predispositions. As an alternative, we use an item asking for respondents' agreement with the following statement: "Schools must teach children to obey authority." While this item is not necessarily an indicator of values defined as motivational goals that transcend situations, replication of the analysis with this indicator, which resembles the child-rearing values, provides further evidence for the robustness of our findings.

The second higher-order value dimension identified by Schwartz - self-transcendence versus self-enhancement - represents a conflict between values that emphasize pro-sociality and equality at the expense of individual interests. Since self-transcendence values emphasize the transcendence of selfish interests in favor of social equality and concern for the welfare of others (Newman et al., 2015a) they have a substantive influence on policies that aim at a more egalitarian distribution of wealth in society (Kulin \& Svallfors, 2013). Therefore, we also control for the effect of self-transcendence values. Again, respondents' self-transcendence scores are subtracted from their self-enhancement scores to capture the relative weight individuals place on self-transcendence.

Subjective perceptions about national or personal economic conditions are widely used as threat indicators in authoritarianism research (Feldman \& Stenner, 1997; Rickert, 1998). We use 
two types of survey questions as measures of perceived economic threat. The first is respondents' estimate of unemployment and poverty levels in their countries. ${ }^{4}$ We use these items as proxies for perceived threats to societal and personal economic well-being. Of course, respondents' estimates of unemployment and poverty may also reflect their knowledge of actual unemployment or poverty in their societies. However, there is also evidence showing that such estimates also reflect individuals' concern with economic conditions in their environment as well as with their own well-being (Conover, Feldman, \& Knight, 1986; Duch, Palmer, \& Anderson, 2000). Our analysis shows that people generally tend to overestimate levels of unemployment in their societies (c.f. Conover, Feldman, \& Knight, 1986; Kunovich, 2012) such that, in our dataset, only 16 percent of respondents correctly estimate unemployment levels in their own country whereas about 73 percent overestimate them. ${ }^{5}$ However, this incorrect estimation does not necessarily mean that people are ignorant about unemployment. In fact, even individuals with low levels of knowledge are generally aware of trends in unemployment levels (Conover, Feldman, \& Knight, 1986; Newman et al., 2015b). People are especially sensitive to levels of unemployment in their immediate locality (Newman et al., 2015b). Therefore, unemployment and poverty estimates may reflect concern with economic conditions in one's immediate setting as

\footnotetext{
${ }^{4}$ The full wording of the questions are as follows: "Of every 100 people of working age in [country] how many would you say are unemployed and looking for work?” and “...do not have enough money for basic necessities?”

${ }^{5}$ Of those who live in countries with 0-4 percent unemployment rates, 22 percent correctly predict the range whereas only 5 percent of those in countries with 5-9 percent unemployment correctly predict this range. Even allowing for room for error and counting the $0-4$ and 10-14 ranges as acceptable, only 34 percent of respondents in countries with unemployment rates between 5-9 percent are able to provide a somewhat accurate estimation of unemployment rates. In countries where the unemployment rate is in the 10-14 percent range, 73 percent of respondents overestimate the range of unemployment.
} 
well as experience of personal economic hardship. We recode the responses to these items to vary between 0 and 1, where 0 indicates the lowest range of perceived unemployment and poverty (0-4 percent) while 1 indicates the highest range (50 percent or more).

The second perceived economic threat variable is a direct measure of personal economic threat perceptions. The ESS asked respondents, on a 5-point Likert scale, how likely it is that during the next 12 months they will a) be unemployed and looking for work, b) not have enough money to cover household necessities, and c) not be able to receive health care if they become ill. We generate an additive index of perceived personal economic threats, where higher scores represent higher levels of perceived threat to personal economic well-being $($ alpha $=.62)$. As with other variables, the final scores are recoded to vary between 0 and 1 .

While these two sets of survey questions capture respondents' subjective perceptions about their country's economic situation or their personal well-being, it is also possible that low levels of income and social class status are associated with personal concerns about one's wellbeing. We therefore also test whether income and social class also moderate the relationship between authoritarian predispositions and support for government responsibility.

In addition to the survey items, we use two country-level economic indicators, inflation (Consumer Price Index, IMF) and unemployment rate (World Bank), which are also among the widely used threat indicators in the authoritarianism literature (Doty, Peterson, \& Winter, 1991; Sales, 1973; Stenner, 2005). Unemployment rates in the dataset vary from 2.6 (Norway) to 11.5 (Turkey) with a mean of 6.52 and a standard deviation of 2.13 and the range of Consumer Price Index (CPI) is between 108.95 (Switzerland) and 434.06 (Ukraine). Since Ukraine's CPI was an outlier and the inclusion of this country inflated the size of the coefficient of main interest, the 
models are run excluding Ukraine from this analysis. Thus, the country with the highest CPI in the models reported in Table 4 is Romania, with a CPI of 280.07.

All models also control for age, gender (1= male), level of education (dummy variables, with low education coded as 1 if the respondent has less than lower secondary education and middle education coded as 1 if the respondent has completed either lower secondary or the second stage of basic or upper secondary), income (10 category income variable coded by the ESS), whether the respondent has any children to take care of at home, union membership, political ideology, and individual religiosity and religious attendance. We also control for respondents' labor market and social class positions. The labor market controls are dummy variables for being retired, unemployed (those who are unemployed and actively looking for work), and not being active in the labor force (including those who are undergoing education, unemployed respondents who are not looking for a job, permanently sick or disabled, those in military or community service, and those doing housework or taking care of family members). Social class categories are coded according to the Oesch 5-class schema, using the detailed ISCO occupation categories available in the ESS (Oesch, 2006). We take small business owners as the reference category and include higher and lower grade service class, and skilled and unskilled worker categories in the models. All individual level variables except for age are recoded to vary between 0 and 1. Summary statistics are presented in Table S1 of the Supplementary Appendix.

At the country level, our primary control variable is the country's communist legacy. This variable is highly correlated with measures of socioeconomic development, such as GDP per capita $^{6}$ and since the degrees of freedom at the country level is rather low, we use this as the only

\footnotetext{
${ }^{6}$ Average GDP per capita was 18,331 USD for countries with a communist legacy and 34,459 USD for other countries.
} 
control variable at the country level. Due to the historical context, one may expect authoritarian predispositions to more closely align with redistributive policies in countries with a communist legacy. To ensure that the results presented below are not driven by the inclusion of postcommunist countries in the dataset, we run all the analyses excluding these countries and find that all the key results are fully replicated in the sub-set of countries with no communist legacy.

Since the income categories in three of the countries in the dataset are not based on deciles, they are not reported in the main dataset. As a result, the following analyses include 27 countries.

\section{Results}

\section{Main effects of authoritarian predispositions}

The first set of analyses test Hypothesis 1, which predicts authoritarian predispositions to be associated with support for redistribution. Table 1 shows the results of the random intercept models ${ }^{7}$. We find that the coefficient for authoritarian predispositions is positive and statistically significant in models predicting support for government responsibility in providing old age (Model 1.1), healthcare (Model 1.2) and unemployment benefits (Model 1.3), as expected. Note that the positive and significant coefficient for authoritarian predispositions is retained after

\footnotetext{
${ }^{7}$ We do not use random slope models because this would have implied that the effect of authoritarianism varied across nations. Since we do not have any substantive theory suggesting that the psychological mechanism that links authoritarianism to redistribution attitudes vary across nations, we use random intercept models. In fact, employing random intercept and random slope models, we find virtually identical estimates (See Table S2 in Supplementary Appendix.)
} 
controlling for many individual-level covariates. ${ }^{8}$ These results are also replicated when using the alternative measure of authoritarian predispositions (see Table S4 of the Supplementary Appendix) and when excluding post-communist countries from the analysis (Table S5 in the Supplementary Appendix).

\section{[Table 1 about here]}

While Johnston, Lavine, \& Federico (2017) find that the effect of closed personality traits, marked by a preference for order, security and certainty, on support for redistribution is conditional on levels of political engagement in the United States, here, we find a direct positive relationship between authoritarian predispositions and support for government responsibility. Their study use measures that are quite similar to ours so the differences in results are unlikely to stem from differences in conceptualization or measurement. There are two possible explanations for the diverging results. First, the two-party system in the United States may enable Republicans and Democrats to bundle issue positions into strictly liberal and conservative agendas whereas the multi-party systems in most European countries may deter political parties from creating such strict bundles. In fact, using data from advanced industrialized countries, Cochrane (2010) finds greater variability among right-wing parties in terms of bundling economic and social issues into a clearly defined left-right dimension. This suggests that party positions and ideological

\footnotetext{
${ }^{8} \mathrm{We}$ also tested the main effects of both authoritarian predisposition variables with no covariates specified in the models. We found that both authoritarianism measures had positive and statistically significant effects on all the dependent variables, showing that the results are not conditional on a particular configuration of control variables used. Table S3 of the Supplementary Appendix presents the results.
} 
configurations in European countries may not necessarily revolve around clearly defined liberal and conservative issue positions as in the United States (also see Bakker, Jolly, \& Polk, 2012). Thus, authoritarian individuals identifying with right or center-right parties in our dataset may find a wider range of economic policy positions to adopt. In fact, Cochrane's analysis of individual positions on social and economic issues shows that a right-wing opinion about the economy is just as likely to accompany left-wing opinions about both immigration and social conservatism in all but one country, the United States. In the United States, there is a clear and statistically significant relationship between social and economic conservatism that is not found in other advanced industrialized countries (Cochrane 2010: 99-100). Unfortunately, since our dataset does not include any countries with a two-party system, ${ }^{9}$ we are unable to provide direct tests of this proposition. Still, in order to examine if party affiliation in a multi-party system has a different effect than a unidimensional left-right ideological orientation, we replace ideology with party affiliation as a control variable. We find that the key associations are all in the expected directions. Individuals who voted for a left party in the most recent election are, on average, more supportive of redistributive policies, and individuals who voted for a right party are less so. Center-voting is associated (negatively) only with unemployment benefits. (For full results please refer to Supplementary Appendix Table S6a, 6b, 6c.)

Despite all the complexities of multi-party systems, given that political competition in Europe occurs more or less along the classical left-right dimension (Benoit \& Laver, 2006; Lefkofridi, Wagner, \& Willmann, 2014), we test whether political engagement, measured as selfreported level of interest in politics, moderate the effect of authoritarian predispositions. We find

\footnotetext{
${ }^{9}$ The countries with the smallest number of effective electoral parties in the closest election year were Spain (2.79) and Hungary (2.8), with all others having more than 3.
} 
that political interest negatively moderates the relationship between authoritarianism and support for healthcare and unemployment benefits, such that as the level of interest in politics increases, the positive relationship between authoritarian orientations and support for redistribution decreases. These findings are in line with existing research that finds stronger issue coherence among individuals with higher levels of political engagement (Cochrane, 2010; Johnston, Lavine, \& Federico 2017; Malka, Lelkes, \& Soto, 2017). We also replicate these results when using the alternative measure of authoritarian predispositions. Full results for these analyses are presented in Tables OA7 and OA8 of the Supplementary Appendix.

The second possible explanation for the direct association between authoritarian predispositions and support for government responsibility is that the ESS data was collected during a global financial crisis. The direct relationship may thus be driven by a heightened sense of material insecurity across the region during this period. To test this, we conduct two separate robustness checks. First, since most countries started to experience severe effects of the crisis in 2009, we repeat the analyses separately for surveys completed in 2008 (about 17,000 interviews in 20 countries) and in 2009 (12,000 interviews in 27 countries). ${ }^{10}$ We also repeat the analyses using the 2016 ESS (albeit on a more restricted set of variables and countries due to data

\footnotetext{
${ }^{10}$ Studies report that the full force of the crisis in terms of unemployment, negative growth, and major bankruptcies did not affect many European countries until 2009. For example, while real GDP growth rates in developed economies and the EU declined from 2.6 percent in 2007 to 0.6 percent in 2008 , a negative growth rate of -3.5 percent was only experienced as late as 2009 (International Labor Office 2010). In Europe, unemployment increased from 5.7 percent in 2007 to 6.0 percent in 2008 and to about 8.4 percent in 2009 . Other social effects of the 2008 economic crisis, such as increased in suicide rates in European countries, were reported for 2009 (Chang et al. 2013).
} 
availability). ${ }^{11}$ Both tests replicate the results of Table 1 , providing further evidence for the direct association between authoritarianism and support for government responsibility in the sample. For details please refer to Supplementary Appendix tables OA9, OA10, and OA11.

\section{Moderating effects of threat}

Next, we move on to test the hypothesis concerning the conditional effect of perceived economic threats. Table 2 presents the models that test for the moderating effect of perceived level of unemployment and poverty on support for government responsibility. Note that all the control variables are also included in these models, although they are not presented in the table. While the authoritarianism variable retains its positive and statistically significant effect on support for old age benefits, its effect is not conditional on perceived unemployment or poverty (Models 2.1 and 2.4 respectively). In fact, a similar finding is reported in Table 3 below in which the moderator variable is personal economic threat perception. Thus, it seems that the relationship between authoritarian orientations and support for old age benefits is not conditional on perceived economic threats.

\section{[Table 2 about here]}

In line with Hypothesis 2, we find both perceived unemployment and perceived poverty to have statistically significant moderating effects in three of the models (see Models 2.3, 2.5, and

\footnotetext{
${ }^{11}$ The level of unemployment in countries included in the dataset ranged from 3.5 percent in Switzerland to 10.14 percent in France, with a mean of 6.38 percent, which is was lower than the EU average (8.5 percent) and close to the OECD average (6.32 percent) for the year 2016.
} 
2.6). In these models, the coefficients of the interactive terms are in the expected direction and statistically different from zero. In Model 2.2, where the dependent variable is support for healthcare benefits, the interaction term also has a positive coefficient, but the standard error is too large to refute the null hypothesis.

To facilitate interpretation of the moderating effects, we plot the conditional effect of authoritarian predispositions on support for healthcare and unemployment benefits in Figure 1. Note that the lowest range of perceived unemployment (0-4 percent) is recoded as 0 while highest range of perceived unemployment reported by respondents (50 percent or higher) is recoded as 1 . As can be seen from the figure, the marginal effect of authoritarian predispositions is positive and statistically different from zero in all models, and the positive relationship between authoritarian orientations and support for healthcare and unemployment become stronger as perceived levels of unemployment and poverty increase. These findings provide support for Hypothesis 2, which predicts perceived economic threats to moderate the relationship between authoritarian predispositions and support for redistribution.

[Figure 1. Moderating effect of perceived unemployment and poverty on authoritarian predispositions and support for healthcare and unemployment benefits (with $95 \%$ confidence intervals]

The models in Table 3 also test Hypothesis 2, but this time using a more direct measure for personal economic threat perceptions. Again, all models in Table 3 control for all the independent variables included in models in Table 1. As is the case with Models 2.1 and 2.4 in Table 2, authoritarianism is positively related to support for old age benefits, yet, its effect is not 
moderated by personal economic threat perceptions (Model 3.1). However, in Models 3.2 and 3.3, we find evidence in support of the conditional effect of economic threat perceptions, as shown by the positive and statistically significant interaction terms. These results suggest that the positive relationship between authoritarian predispositions and support for government responsibility to provide healthcare benefits and a decent standard of living for the unemployed is stronger for individuals who believe that their own economic prospects are in jeopardy. Thus, the findings in Table 3 mostly replicate the findings in Table 2, providing further support for Hypothesis 2. The results in Tables 2 and 3 are also replicated when using the alternative measure for authoritarian predispositions (see Tables OA12 and OA13 in Supplementary Appendix) and when excluding post-communist countries from the analysis (see Tables OA14 and OA15 in Supplementary Appendix).

\section{[Table 3 about here]}

In addition to subjective threat perceptions, we also test whether income or social class moderate the relationship between authoritarian orientations and attitudes towards redistribution. Individuals with lower incomes and social class positions may experience greater levels of economic insecurity. In addition, those with higher income may feel that they have more to lose from redistribution because they will have to pay for the costs of these redistributive policies. We test these considerations by adding interaction terms between authoritarian predispositions and income (Supplementary Appendix Table S16) as well as social class position variables (Supplementary Appendix Table S17). We find that income negatively moderates the relationship between authoritarian predispositions and support for old age and healthcare benefits such that 
the positive relationship between authoritarian predispositions and support for redistribution becomes weaker as the respondent's level of income increases. This finding is in line with the expectations laid out in Hypothesis 2. However, we are unable to replicate this finding for support for unemployment benefits: although the coefficients are in the expected directions, they are not statistically different from zero.

\section{[Table 4 about here]}

Finally, we use the country-level economic hardship indicator, the consumer price index (see Doty, Peterson, \& Winter, 1991; Sales, 1973; Stenner, 2005), as an alternative measure for economic threat and test whether this variable moderates the relationship between authoritarian predispositions and support for redistribution (See Table 4). We find the coefficient of inflation to be null in Models 4.1-4.3, suggesting that, all else being equal, higher levels of inflation are not necessarily associated with higher levels of support for redistribution at the individual level. Yet, the conditional effect of inflation on authoritarian predispositions and support for government responsibility is positive and statistically significant in all of the models (Models 4.4-4.6). Figure 2 plots these conditional effects. The $\mathrm{x}$-axis plots the level of the consumer price index while the $y$-axis shows the marginal effect of the coefficient of authoritarian predispositions on support for healthcare and unemployment benefits. The figure shows that, authoritarian predispositions have a positive, statistically significant effect on support for government responsibility in providing healthcare and unemployment benefits for all levels of the consumer price index, as expected. This effect becomes stronger as the value of the index rises (i.e. as inflation increases). This evidence is in line with Hypothesis 2 and earlier findings, which show that higher levels of 
economic threat are associated with a stronger association between authoritarian orientations and support for redistributive policies. Note that the results in Table 4 are also fully replicated when using the alternative measure of authoritarian orientations (See Table S18 in Supplementary Appendix). ${ }^{12}$

[Figure 2. Moderating effect of consumer price index on authoritarian

\section{predispositions and support for healthcare and unemployment benefits (with $95 \%$ confidence intervals)]}

We replicate the analysis in Table 4 using an alternative measure of national economic conditions, unemployment. The results are presented in Supplementary Appendix Table S19. We find that the coefficients of the interactive terms are positive, as predicted, yet none of these interaction terms turn out to be statistically different from zero. It is possible that relatively low degrees of freedom at the country level may lead to high standard errors for the interaction terms. It is also possible that while national inflation rates reflect a level of economic hardship felt by more or less everyone, national unemployment rates may not capture the hardship felt by those in different localities. In fact there is evidence that individuals are more sensitive towards unemployment in their immediate locality (Newman et al., 2015b). If this is the case, it may explain the null findings for the interactions between national unemployment levels and authoritarian predispositions.

\footnotetext{
${ }^{12}$ Since the number of observations at the country level decreases to 16 when post-communist countries are excluded, and since this model includes a cross-level interaction, we do not repeat this analysis when excluding the post-communist countries from the model.
} 


\section{Auxiliary analyses}

Attitudes towards redistribution may not only be susceptible to economic threats. In fact, any sufficiently salient threat that disrupts the normative order could act as a catalyst between authoritarian predispositions and security and safety seeking behavior. Previous research on the effects of threat on opinions utilized crime rates (Rocatto, Vieno, \& Russo, 2014), fear of terrorism (Hetherington \& Suhay, 2011) and even simple fear of failure (Sales \& Friend, 1973). Thus, there is evidence that various forms of threat are associated with safety and certainty seeking attitudes. While our focus here is on the moderating effects of economic threat, we also test whether generic threat perception, measured with respondents' feeling of safety walking alone in their locality after dark, is a significant moderator. We find that the positive effect of authoritarian dispositions on support for old age and healthcare benefits is stronger for individuals who feel more unsafe in their locality. For results, see Supplementary Appendix Table S20.

Authoritarian orientations are also associated with exclusionary views towards outgroups. While we provide evidence that those with authoritarian orientations are willing to support redistributive policies for unspecified beneficiaries, we may expect these individuals to be less supportive of redistributive policies if the recipients are members of out-groups that are seen as being undeserving. Unfortunately there are no survey items in the ESS that distinguish between the recipients of redistributive policies. However, as a proxy test, we use an item that taps respondent's perception of deservingness of welfare beneficiaries as moderator. ${ }^{13} \mathrm{We}$ find

\footnotetext{
${ }^{13}$ This item taps respondents' agreement with the statement: Many try to obtain benefits / services that they are not entitled to.
} 
that agreement with the statement that welfare recipients are undeserving weakens the positive effect of authoritarian predispositions on support for healthcare and unemployment benefits. (See Table S21 for full results) This provides some evidence that the perceived characteristics of welfare beneficiaries can moderate the effect of authoritarian predispositions on support for some benefits. This implies that authoritarian support for redistributive policies may be differentially conditional on recipient characteristics.

It is not uncommon for immigrants to be portrayed as undeserving recipients of social benefits in many European countries. If immigrants are generally seen as undeserving recipients, we may expect higher levels of immigration to negatively moderate the effect of authoritarianism. We in fact find that the positive effect of authoritarian predispositions on support for old age and healthcare benefits dampens as the percentage of foreign born population in 2005 increases. This finding is replicated when using the alternative authoritarianism measure and when using the percentage of foreign-born population in 2010. We report the full results of these analyses in Supplementary Appendix Table S22.

\section{Discussion and Conclusion}

Authoritarian predispositions have generally been considered in relation to their effects on prejudice, intolerance and out-group hostility. While some researchers have recently extended the application of authoritarianism to other political attitudes, such as support for democracy (Canetti-Nisim \& Beit-Hallahmi, 2007), rejection of civil liberties (Hetherington \& Weiler, 2009), and political participation and engagement (Federico, Fisher, \& Deason 2017; Gutting, 2019; Weiner \& Federico, 2017), relatively little is known about its relationship with economic attitudes. Using cross-national data from the European Social Surveys, we show that authoritarian 
orientations are positively associated with support for government responsibility for old age, healthcare and unemployment benefits and that these associations are generally stronger in the presence of perceived economic threat. These results replicate when controlling for a host of individual-level predictors, using different measures of authoritarianism, and when excluding post-communist countries from the analysis.

Most existing studies have associated support for redistribution with values such as egalitarianism or humanitarianism (Achterberg, Houtman, and Derks 2011; Feldman and Steenbergen 2001; Kulin and Svallfors 2013). Recently, some works questioned the conventional wisdom that redistribution necessarily reflects the values associated with concern for the wellbeing of others or equality (Jensen 2014; Schmidt 2010). They also suggested that politically conservative elites or political parties may not always hold anti-welfare positions. In fact, there are many instances of political elites and mass publics, including populist right-wing parties opposing such principles yet simultaneously embracing other dimensions of active government interference in the economy (Federico, Johnston, \& Lavine, 2016; Lipset, 1959; Oesch 2008). Our findings show that, at the mass level, authoritarian orientations are not necessarily opposed to redistributive policies. Especially when economic grievances are high, political parties or candidates running on protectionist economic platforms may hope to cultivate support from those with authoritarian dispositions. Thus, we can at least partially explain the recent support garnered by right-wing populist parties or candidates that combine anti-immigrant, exclusionary rhetoric with protectionist economic policies (Federico, Johnston, \& Lavine, 2016).

Finally, our results also contribute to the debate on the structure and nature of ideology and are in line with some recent works showing that left and right-wing ideologies are not necessarily mirror images of each another (Federico \& Malka, 2018; Malka et al., 2015; Malka, 
Lelkes, \& Soto, 2017). These studies show that economically liberal policies are not necessarily related to socially conservative policies among political parties and the masses in various contexts. Our findings take this a step further by showing that authoritarian orientations, which are related to socially conservative attitudes, may also be associated with economically liberal attitudes and that this association is even stronger when individuals are economically threated. Thus, we can expect more variability in the way mass attitudes are structured over time and across nations. If those with authoritarian tendencies who prefer socially conservative policies desire more economically liberal policies in times of economic threat, we may observe greater variance in a two-dimensional issue space during these periods. Future studies could investigate whether economically threatening times or contexts lead a more heterogeneous (twodimensional) ideological space among both the masses and political parties or candidates.

That said our study has several limitations. First, our data comes primarily from European countries although a few non-European cases, such as Russia, Ukraine and Israel are also included. Therefore, we are unable to assess the relationship between authoritarian orientations and support for redistribution in other contexts. Second, the measures that we use do not enable us to clearly distinguish between different types of threat. While one of our measures combines direct assessments of personal economic worries, perceived unemployment and poverty rates provide only proxy measures of economic threat perceptions. It is also unclear whether or to what extent these latter measures reflect concern with societal economic well-being (well-being in one's immediate setting, as suggested by Newman et al., 2015) as opposed to pocketbook economic considerations. ${ }^{14}$ Even if we had more fine-tuned measures of pocketbook and

\footnotetext{
${ }^{14}$ See for example Conover, Feldman, \& Knight, 1986, and Duch, Palmer, \& Anderson, 2000, who conclude that estimates of unemployment at least partly reflect one's general level of economic well-being.
} 
sociotropic economic threat perceptions, threat measures are often endogenous. Individuals who are personally insecure also tend to report threat to collective economic well-being (Sniderman, Hagendoorn, \& Prior, 2004). We are therefore unable to tease out what type of economic threat perceptions moderate the relationship between authoritarian orientations and support for redistribution. Future studies could utilize experimental methods for more fine-tuned tests of the moderating effects of different types of threat perceptions.

Finally, our auxiliary analyses point to a more complex dynamic between authoritarianism and attitudes towards redistribution. Authoritarian predispositions push towards security and certainty in times of higher threat, hence the positive moderating effects. However, authoritarians may also respond to political discourse that portrays immigrants as out-group members undeserving of social benefits, hence the negative moderation effects. While we are unable to provide direct tests, there is evidence that the positive relationship between authoritarian orientations and support for redistribution may be conditional on who the perceived beneficiaries are. The analyses provide some evidence that authoritarians may not be willing to support redistributive policies if recipients are seen as being out-groups or undeserving, but due to data limitations, we are not able to provide direct evidence. Future studies could further investigate the complex dynamic between recipient characteristics, authoritarianism and threat perceptions. A more nuanced approach could also help us understand and explain the rise of populist right parties that combine strong anti-immigration policies with commitment to welfare.

\section{References}


Achterberg, Peter, Dick Houtman, and Anton Derks. 2011. "Two of a Kind? An Empirical Investigation of Anti-Welfarism and Economic Egalitarianism." The Public Opinion Quarterly 75(4): 748-760.

Adorno, Theodor W., Daniel J. Levinson, Nevitt Sanford, and Else Frenkel-Brunswik. 1950. The Authoritarian Personality. New York: Norton.

Altemeyer, Bob. 1981. Right-Wing Authoritarianism. Winnipeg: University of Manitoba Press.

Altemeyer, Bob. 1996. The Authoritarian Specter. Cambridge, MA: Harvard University Press.

Arikan, Gizem. (2013). "Values, Religiosity, and Support for Redistribution and Social Policy in Turkey." Turkish Studies 14(1): 34-52.

Arikan, Gizem, and Pazit Ben-Nun Bloom. 2015. "Social Values and Cross-National Differences in Attitudes towards Welfare.” Political Studies 63(2):431-448.

Bakker, Ryan, Seth Jolly, and Jonathan Polk. 2012. "Complexity in the European Party Space: Exploring Dimensionality with Experts.” European Union Politics 13(2): 219-245.

Benoit, Kenneth and Michael Laver. 2006. Party Policy in Modern Democracies. London: Routledge.

Canetti-Nisim, Daphna, and Benjamin Beit-Hallahmi. 2007. "The Effects of Authoritarianism, Religiosity, and "New Age" Beliefs on Support for Democracy: Unraveling the Strands." Review of Religious Research 48:369-384.

Chang, Shu-Sen, David Stuckler, Paul Yip, and David Gunnell. 2013. "Impact of 2008 Global Economic Crisis on Suicide: Time Trend Study in 54 countries.” BMJ 347:f5239. 
Cizmar, Anne M., Geoffrey C. Layman, John McTague, Shanna Pearson-Merkowitz, and Michael Spivey. 2014. "Authoritarianism and American Political Behavior from 1952 to 2008." Political Research Quarterly 67(1):71-83.

Cochrane, Christopher. 2010. Left/Right Asymmetries in a Multidimensional Universe: Citizens, Activists, and Parties. Doctoral Dissertation. University of Toronto.

Cohrs, J. Christopher, Barbara Moschner, Jürgen Maes, and Sven Kielmann. 2005. "The Motivational Bases of Right-Wing Authoritarianism and Social Dominance Orientation: Relations to Values and Attitudes in the Aftermath of September 11, 2001.” Personality and Social Psychology Bulletin 31(10):1425-1434.

Conover, Pamela Johnston, Stanley Feldman, and Kathleen Knight. 1986. “Judging Inflation and Unemployment: The Origins of Retrospective Evaluations.” The Journal of Politics 48(3):565-588.

Davies, James C. 1962. "Toward a Theory of Revolution.” American Sociological Review 27(1): 5-19.

Doty, Richard M., Bill E. Peterson, and David G. Winter. 1991. "Threat and Authoritarianism in the United States, 1978-1987.” Journal of Personality and Social Psychology 61(4): 629640.

Dryzek, John, and Robert E. Goodin. 1986. "Risk-Sharing and Social Justice: The Motivational Foundations of the Post-War Welfare State.” British Journal of Political Science 16(1): 134. 
Duch, Raymond M., Harvey D. Palmer, and Christopher J. Anderson. 2000. "Heterogeneity in Perceptions of National Economic Conditions." American Journal of Political Science 44(4): 635-652.

Duckitt, John. 1989. "Authoritarianism and Group Identification: A New View of an Old Construct." Political Psychology 10(1): 63-84.

Duckitt, John. 1992. “Threat and Authoritarianism: Another Look." The Journal of Social Psychology 132(5): 697-698.

Duckitt, John. 2001. "A Dual-Process Cognitive-Motivational Theory of Ideology and Prejudice.” Advances in Experimental Social Psychology 33(1): 41-113.

Duckitt, John, and Chris G. Sibley. 2007. "Right Wing Authoritarianism, Social Dominance Orientation and the Dimensions of Generalized Prejudice." European Journal of Personality 21(2): 113-130.

Duriez, Bart, and Alain Van Hiel. 2002. "The March of Modern Fascism: A Comparison of Social Dominance Orientation and Authoritarianism." Personality and Individual Differences 32(7): 1199-1213.

Esping-Andersen, Gøsta. 1990. The Three Worlds of Welfare Capitalism. Cambridge: Polity Press.

Federico, Christopher M., Emily L. Fisher, and Grace Deason. 2011. "Expertise and the Ideological Consequences of the Authoritarian Predisposition." Public Opinion Quarterly 75(4): 686-708. 
Federico, Christopher M., Emily L. Fisher, and Grace Deason. 2017. "The Authoritarian Left Withdraws from Politics: Ideological Asymmetry in the Relationship between Authoritarianism and Political Engagement.” The Journal of Politics 79(3): 1010-1023.

Federico, C., Johnston, C., \& Lavine, H. (2016). Here's Why Trump's Supporters Tolerate His “Liberal” Economic Positions. Washington Post, March 8.

Federico, Christopher M., and Ariel Malka. 2018. "The Contingent, Contextual Nature of the Relationship between Needs for Security and Certainty and Political Preferences: Evidence and Implications.” Advances in Political Psychology 39(1): 3-47.

Feldman, Stanley. 2003. "Enforcing Social Conformity: A Theory of Authoritarianism.” Political Psychology 24(1): 41-74.

Feldman, Stanley. 2013. "Authoritarianism in Social Context: The Role of Threat.” International Journal of Psychology 48(1): 55-59.

Feldman, Stanley, and Christopher Johnston. 2014. "Understanding the Determinants of Political Ideology: Implications of Structural Complexity.” Political Psychology 35(3): 337-358.

Feldman, Stanley, and Marco R. Steenbergen. 2001. "The Humanitarian Foundation of Public Support for Social Welfare". American Journal of Political Science 45:658.

Feldman, Stanley, and Karen Stenner. 1997. "Perceived Threat and Authoritarianism.” Political Psychology 18(4): 741-770. 
Gutting, Raynee Sarah. 2019. “Contentious Activities, Disrespectful Protesters: Effect of Protest Context on Protest Support and Mobilization across Ideology and Authoritarianism.” Political Behavior. Forthcoming. https://doi.org/10.1007/s11109-018-09523-8.

Hetherington, Marc, and Elizabeth Suhay. 2011. "Authoritarianism, Threat, and Americans' Support for the War on Terror.” American Journal of Political Science 55(3): 546-560.

Hetherington, Marc J. and Jonathan D. Weiler. 2009. Authoritarianism and Polarization in American Politics. Cambridge, UK: Cambridge University Press.

International Labor Office. 2010. Global Employment Trends. Geneva.

Johnston, Christopher D., Howard Lavine, and Christopher M. Federico. 2017. Open Versus Closed: Personality, Identity, and the Politics of Redistribution. Cambridge: Cambridge University Press.

Johnston, Christopher D., and Julie Wronski. 2015. "Personality Dispositions and Political Preferences across Hard and Easy Issues.” Political Psychology 36(1): 35-53.

Jost, John T., Jack Glaser, Arie W. Kruglanski, and Frank J. Sulloway. 2003. "Political Conservatism as Motivated Social Cognition." Psychological Bulletin 129(3): 339-375.

King, Desmond, and Fiona Ross. 2010. "Critics and Beyond.” In Francis G. Castles, Stephan Leibfreid, Jane Lewis, Herbert Obinger and Christopher Pierson (Eds.), Oxford Handbook of the Welfare State. Oxford, United Kingdom: Oxford University Press, pp. 46-58.

Kunovich, Robert M. 2012. "Perceived Unemployment.” International Journal of Sociology 42(4): 100-123. 
Kulin, Joakim, and Stefan Svallfors. 2013. "Class, Values, and Attitudes towards Redistribution: A European Comparison.” European Sociological Review 29(2):155-167.

Lefkofridi, Zoe, Markus Wagner, and Johanna E. Willmann. 2014. "Left-Authoritarians and Policy Representation in Western Europe: Electoral Choice across Ideological Dimensions." West European Politics 37(1): 65-90.

Lipset, Seymour Martin. 1959. "Democracy and Working-Class Authoritarianism". American Sociological Review 24(4): 482-501.

Lipset, Seymour Martin. 1997. American Exceptionalism: A Double-Edged Sword. New York: W.W. Norton and Company.

Malka, Ariel, Yphtach Lelkes, and Christopher J. Soto. 2017. “Are Cultural and Economic Conservatism Positively Correlated? A Large-Scale Cross-National Test.” British Journal of Political Science. DOI: 10.1017/S0007123417000072.

Malka, Ariel, and Christopher J. Soto. 2015. "Rigidity of the Economic Right? MenuIndependent and Menu-Dependent Influences of Psychological Dispositions on Political Attitudes." Current Directions in Psychological Science 24(2):137-142.

Newman, Benjamin J., Todd K. Hartman, Patrick Lown, and Stanley Feldman. 2015a. "Easing the Heavy Hand: Humanitarian Concern, Empathy, and Opinion on Immigration.” British Journal of Political Science 45(3): 583-607.

Newman, Benjamin J., Yamil Velez, Todd K. Hartman, and Alexa Bankert. 2015b. “Are Citizens 'Receiving The Treatment?' Assessing a Key Link in Contextual Theories of Public Opinion and Political Behavior." Political Psychology 36(1): 123-131. 
Oesch, Daniel. 2006. Redrawing the Class Map. Stratification and Institutions in Britain, Germany, Sweden and Switzerland. Basingstoke: Palgrave Macmillan.

Oesch, Daniel. 2008. 'Explaining Workers' Support for Right-Wing Populist Parties in Western Europe: Evidence from Austria, Belgium, France, Norway, and Switzerland.” International Political Science Review 29(3): 349-373.

Reich, Wilhelm. 1946. The Mass Psychology of Fascism. Orgone Institute Press.

Rickert, Edward J. 1998. “Authoritarianism and Economic Threat: Implications for Political Behavior." Political Psychology 19(4): 707-720.

Rocatto, Michelle, Alessio Vieno, and Silvia Russo. 2014. “The Country's Crime Rate Moderates the Relation Between Authoritarian Predispositions and the Manifestations of Authoritarianism: A Multilevel, Multinational Study.” European Journal of Personality 28: 14-24.

Sales, Stephen M. 1973. "Threat as a Factor in Authoritarianism: An Analysis of Archival Data." Journal of Personality and Social Psychology 28(1): 44-57.

Sales, Stephan M., \& Friend, Kenneth E. (1973). "Success and Failure as Determinants of Level of Authoritarianism." Behavioral Science 18:163-172.

Schwartz, Shalom H. 1992. "Universals in the Content and Structure of Values: Theoretical Advances and Empirical Tests in 20 Countries." Advances in Experimental Social Psychology 25(1):1-65. 
Sniderman, Paul M., Louk Hagendoorn, and Markus Prior. 2004. Predisposing Factors and Situational Triggers: Exclusionary Reactions to Immigrant Minorities. American Political Science Review 98(1): 35-49.

Stenner, Karen. 2005. The Authoritarian Dynamic. New York: Cambridge University Press.

Stenner, Karen. 2009. "Three Kinds of 'Conservatism.'” Psychological Inquiry 20(2-3): 142159.

Stevens, Daniel, Benjamin G. Bishin, and Robert R. Barr. 2006. "Authoritarian Attitudes, Democracy, and Policy Preferences among Latin American Elites.” American Journal of Political Science 50(3):606-620.

Treier, Shawn, and Sunshine Hillygus. 2009. "The Nature of Political Ideology in the Contemporary Electorate.” Public Opinion Quarterly 73(4): 679-703.

Van der Brug, Wouter, and Joost Van Spanje. 2009. "Immigration, Europe and the 'New' Cultural Dimension.” European Journal of Political Research 48(3): 309-334.

Van Hiel, Alain, Bart Duriez, and Malgorzata Kossowska. 2006. "The Presence of Left-Wing Authoritarianism in Western Europe and Its Relationship with Conservative Ideology.” Political Psychology 27(5): 769-793.

Weiner, Elliot, and Christopher M. Federico. 2017. “Authoritarianism, Institutional Confidence, and Willingness to Engage In Collective Action”. Personality And Social Psychology Bulletin 43:392-406. 
Figure 1. Moderating effect of perceived unemployment and poverty on authoritarian predispositions and support for healthcare and unemployment benefits (with $95 \%$ confidence intervals) 

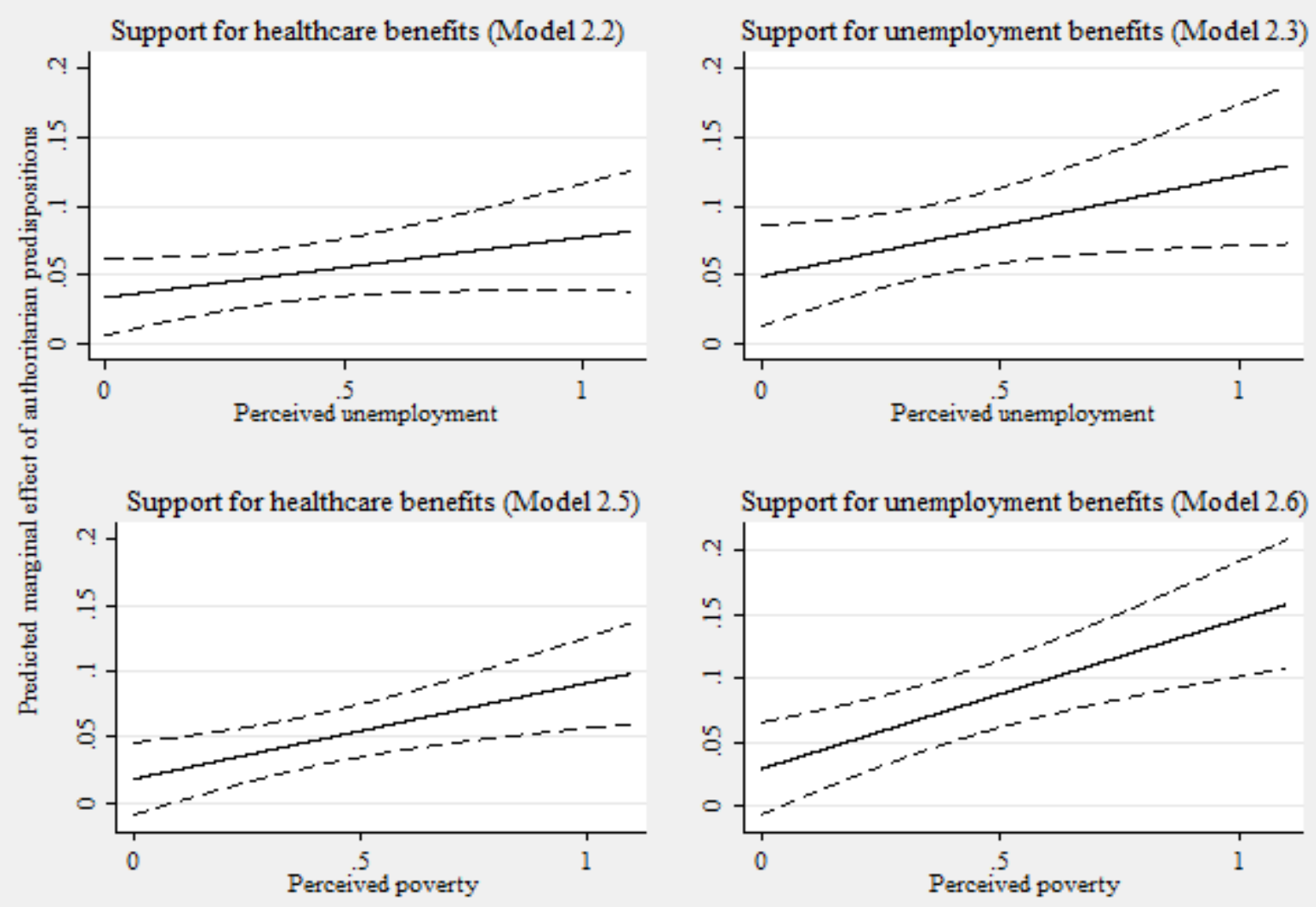

Figure 2. Moderating effect of consumer price index on authoritarian predispositions and support for healthcare and unemployment benefits (with 95\% confidence intervals) 

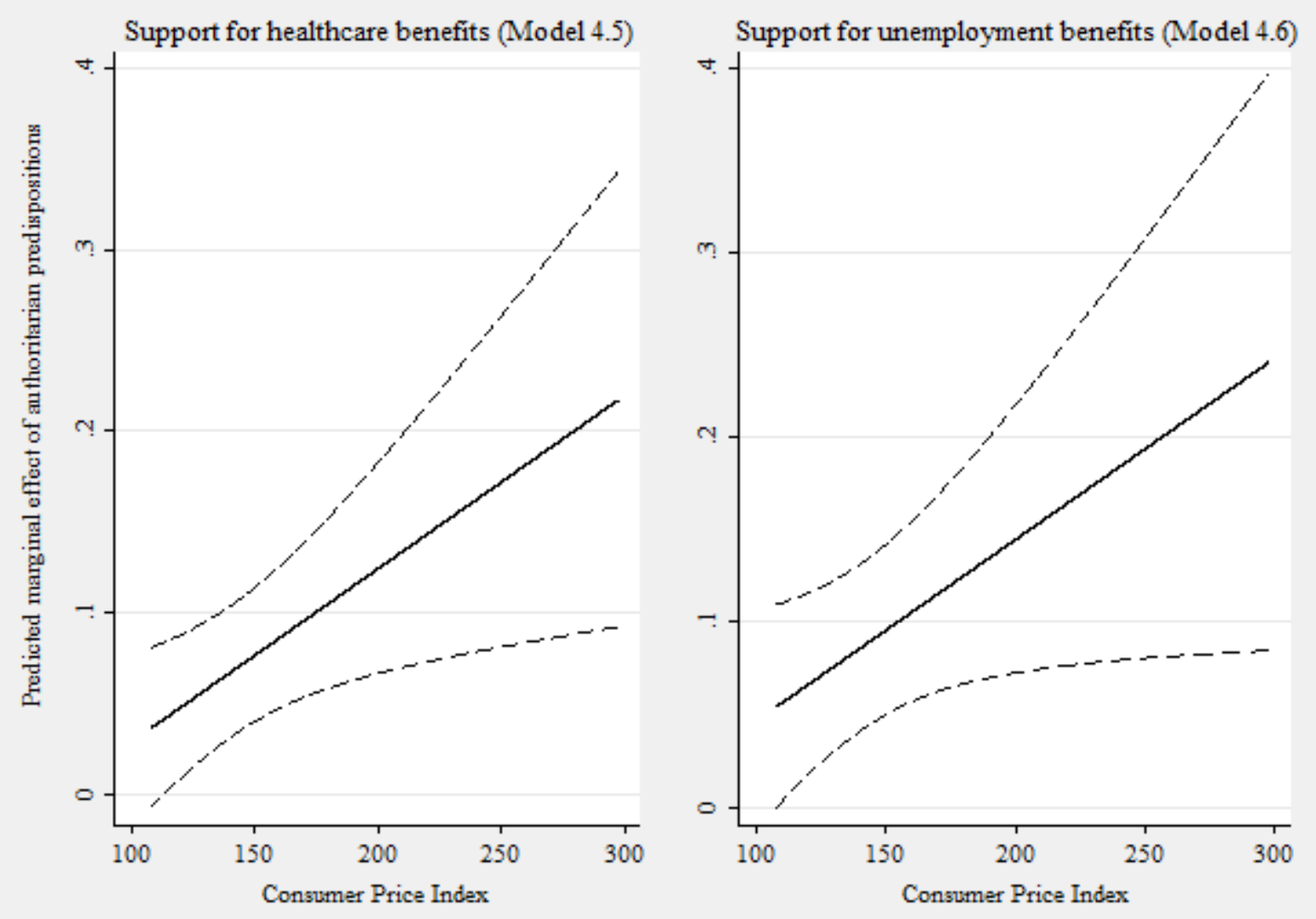

Table 1. Authoritarian predispositions and support for redistribution: random intercept models

\begin{tabular}{|c|c|c|}
\hline & $\begin{array}{l}1.2 \text { Support for } \\
\text { healthcare }\end{array}$ & $\begin{array}{l}1.3 \text { Support for } \\
\text { unemployment }\end{array}$ \\
\hline
\end{tabular}




\begin{tabular}{|c|c|c|c|}
\hline & & benefits & benefits \\
\hline Constant & $.744(.014)^{* *}$ & $.779(.013)^{* *}$ & $.602(.021)^{* *}$ \\
\hline \multicolumn{4}{|l|}{ Demographic variables } \\
\hline Age & $-.000(.000)^{*}$ & $-.000(.000)^{* *}$ & $-.000(.000)$ \\
\hline Gender $($ Male $=1)$ & $-.005(.002)^{* *}$ & $-.001(.002)$ & $-.001(.003)$ \\
\hline Low education & $.008(.004)^{* *}$ & $-.005(.004)$ & $.007(.005)$ \\
\hline Medium education & $.009(.002)^{* *}$ & $-.001(.002)$ & $.006(.003)^{* *}$ \\
\hline Income & $-.021(.004)^{* *}$ & $-.005(.004)$ & $-.041(.005)^{* *}$ \\
\hline Child at home & $.001(.002)$ & $.002(.002)$ & $-.001(.003)$ \\
\hline Union membership & $.017(.002)^{* *}$ & $.015(.002)^{* *}$ & $.014(.003)^{* *}$ \\
\hline \multicolumn{4}{|l|}{$\begin{array}{l}\text { Labor market and social } \\
\text { class variables }\end{array}$} \\
\hline Retired & $.005(.003)$ & $.003(.003)$ & $.013(.004)^{* *}$ \\
\hline Unemployed & $.011(.005)^{* *}$ & $.017(.005)^{* *}$ & $.053(.006) * *$ \\
\hline Not in paid work & $.001(.003)$ & $.003(.003)$ & $.011(.004)^{* *}$ \\
\hline Higher-grade service & $-.010(.004)^{* *}$ & $-.003(.004)$ & $.018(.005)^{* *}$ \\
\hline Lower-grade service & $.002(.003)$ & $-.002(.004)$ & $.020(.005)^{* *}$ \\
\hline Skilled workers & $.003(.003)$ & $-.002(.003)$ & $.022(.004)^{* *}$ \\
\hline Unskilled workers & $.007(.004)^{*}$ & $.000(.004)$ & $.030(.005)^{* *}$ \\
\hline \multicolumn{4}{|l|}{ Social \& political orientations } \\
\hline Ideology (Left-right) & $-0.032(.004)^{* *}$ & $-.034(.004) * *$ & $-.083(.006)^{* *}$ \\
\hline Self-transcendence & $0.133(.010)^{* *}$ & $.150(.010)^{* *}$ & $.134(.013)^{* *}$ \\
\hline Authoritarian predispositions & $0.066(.010)^{* *}$ & $.055(.010)^{* *}$ & $.083(.013)^{* *}$ \\
\hline Religiosity & $0.014(.004)^{* *}$ & $.003(.004)$ & $.020(.005)^{* *}$ \\
\hline Religious attendance & $-0.032(.004)^{* *}$ & $-.026(.004)^{* *}$ & $-.007(.006)$ \\
\hline \multicolumn{4}{|l|}{ Country-level variables } \\
\hline Post-communist country & $.044(.018)^{* *}$ & $.025(.016)$ & $.032(.028)$ \\
\hline \multicolumn{4}{|l|}{ Random effect parameters } \\
\hline Constant & $.046(.006)^{* *}$ & $.042(.006)^{* *}$ & $.073(.010)^{* *}$ \\
\hline Individual level & $.160(.001)^{* *}$ & $.157(.001)^{* *}$ & $.206(.001)^{* *}$ \\
\hline$-2 \times$ Log Likelihood & -24520.30 & -25728.94 & -9534.76 \\
\hline N. Level-1 / N. Level 2 & $29837 / 27$ & $29838 / 27$ & 29745 / 27 \\
\hline
\end{tabular}

Entries are non-standardized coefficients with standard errors in parentheses. $*_{p}<0.1, *^{*} p<0.05$ (2-tailed). 
Table 2. Authoritarian predispositions and support for redistribution: moderating effect of perceived level of unemployment and poverty

\begin{tabular}{|c|c|c|c|c|c|c|}
\hline & $\begin{array}{l}\text { 2.1 Support } \\
\text { for old age } \\
\text { benefits }\end{array}$ & $\begin{array}{l}\text { 2.2 Support } \\
\text { for healthcare } \\
\text { benefits }\end{array}$ & $\begin{array}{l}2.3 \text { Support } \\
\text { for unemploy- } \\
\text { ment benefits }\end{array}$ & $\begin{array}{l}\text { 2.4 Support } \\
\text { for old age } \\
\text { benefits }\end{array}$ & $\begin{array}{l}2.5 \text { Support } \\
\text { for healthcare } \\
\text { benefits }\end{array}$ & $\begin{array}{l}\text { 2.6 Support } \\
\text { for unemploy- } \\
\text { ment benefits }\end{array}$ \\
\hline Constant & $.723 .(.015)^{* *}$ & $.781(.014)^{* *}$ & $.594(.021)^{* *}$ & $.721(.014)^{* *}$ & $.783(.014)^{* *}$ & $.604(.021)^{* *}$ \\
\hline \multicolumn{7}{|c|}{ Individual-level variables } \\
\hline Ideology (left-right) & $-.031(.005)^{* *}$ & $-.033(.005)^{* *}$ & $-.081(.006)^{* *}$ & $-.029(.005)^{* *}$ & $-.032(.005)^{* *}$ & $-.079(.006)^{* *}$ \\
\hline Self-transcendence & $.134(.010)^{* *}$ & $.147(.010)^{* *}$ & $.135(.013) * *$ & $.124(.010)^{* *}$ & $.141(.010)^{* *}$ & $.123(.013)^{* *}$ \\
\hline $\begin{array}{l}\text { Perceived } \\
\text { unemployment }\end{array}$ & $.058(.015)^{* *}$ & $.001(.015)$ & $.014(.020)$ & - & - & - \\
\hline $\begin{array}{l}\text { Perceived } \\
\text { unemployment } \mathrm{x} \\
\text { Authoritarian } \\
\text { predispositions }\end{array}$ & $-.018(.028)$ & $.044(.027)$ & $.073(.036)^{* *}$ & - & - & - \\
\hline $\begin{array}{l}\text { Post-communist } \\
\text { country } \\
\text { Random effect paramete }\end{array}$ & $.040(.017)^{* *}$ & $.023(.016)^{* *}$ & $.025(.027)$ & $.032(.017)^{* *}$ & $.018(.016)$ & $.019(.027)$ \\
\hline Constant & $.043(.006)^{* *}$ & $.040(.006)^{* *}$ & $.071(.010)$ & $.042(.006)^{* *}$ & $.040(.005)^{* *}$ & $.069(.009)^{* *}$ \\
\hline Individual level & $.159(.001)^{* *}$ & $.156(.001)^{* *}$ & $.204(.001)$ & $.159(.001)^{* *}$ & $.156(.001)^{* *}$ & $.204(.001)^{* *}$ \\
\hline$-2 \times$ Log Likelihood & -23783.01 & -24994.72 & -9465.56 & -24063.84 & -24999.58 & -9594.46 \\
\hline
\end{tabular}

Models include all demographic controls (age, gender, levels of education, income, labor market and social class variables, union membership), as well as religiosity and religious attendance. Entries are non-standardized coefficients with standard errors in parentheses. $* p<0.1$, $* * p<0.05(2$-tailed). 
Table 3. Authoritarian predispositions and support for redistribution: moderating effect of personal economic threat perceptions

\begin{tabular}{llll}
\hline & $\begin{array}{l}\text { 3.1 Support for } \\
\text { old age benefits }\end{array}$ & $\begin{array}{l}\text { 3.2 Support for } \\
\text { healthcare } \\
\text { benefits }\end{array}$ & $\begin{array}{l}\text { 3.3 Support for } \\
\text { unemployment } \\
\text { benefits }\end{array}$ \\
\hline Constant & $.748(.015)^{* *}$ & $.801(.014)^{* *}$ & $.599(.022)^{* *}$ \\
$\begin{array}{l}\text { Individual-level variables } \\
\text { Ideology (left-right) }\end{array}$ & $-.037(.005)^{* *}$ & $-.040(.004)^{* *}$ & $-.087(.006)^{* *}$ \\
Self-transcendence & $.127(.010)^{* *}$ & $.144(.010)^{* *}$ & $.133(.013)^{* *}$ \\
Authoritarian predispositions & $.052(.014)^{* *}$ & $.021(.013)$ & $.051(.018)^{* *}$ \\
Personal economic threat & $.002(.016)$ & $-.041(.017)^{* *}$ & $.001(.022)$ \\
Personal economic threat $\mathrm{x}$ & $.013(.017)$ & $.086(.032)^{* *}$ & $.087(.041)^{* *}$ \\
Authoritarian predispositions & & & \\
Country-level variables & & & $.023(.028)$ \\
Post-communist country & $.019(.032)$ & $.024(.016)$ & $.072(.010)^{* *}$ \\
Random effect parameters & & & $.206(.001)^{* *}$ \\
Constant & $.045(.006)^{* *}$ & $.041(.006)^{* *}$ & \\
Individual level & $.159(.001)^{* *}$ & $.156(.001)^{* *}$ & \\
& & & -9499.71 \\
-2 x Log Likelihood & -23536.32 & -24644.15 & $28113 / 27$ \\
N. Level-1 / N. Level 2 & $28184 / 27$ & $28186 / 27$ & \\
\hline
\end{tabular}

Models include all demographic controls (age, gender, levels of education, income, labor market and social class variables, union membership), as well as religiosity and religious attendance. Entries are non-standardized coefficients with standard errors in parentheses. $* p<0.1$, $* *<<0.05$ (2-tailed). 
Table 4. Authoritarian predispositions and support for redistribution: moderating effect of inflation

\begin{tabular}{|c|c|c|c|c|c|c|}
\hline & $\begin{array}{l}\text { 4.1 Support for } \\
\text { old age } \\
\text { benefits }\end{array}$ & $\begin{array}{l}\text { 4.2 Support for } \\
\text { healthcare } \\
\text { benefits }\end{array}$ & $\begin{array}{l}\text { 4.3 Support for } \\
\text { unemploy- } \\
\text { ment benefits }\end{array}$ & $\begin{array}{l}\text { 4.4 Support for } \\
\text { old age } \\
\text { benefits }\end{array}$ & $\begin{array}{l}\text { 4.5 Support } \\
\text { for healthcare } \\
\text { benefits }\end{array}$ & $\begin{array}{l}\text { 4.6 Support for } \\
\text { unemploy- } \\
\text { ment benefits }\end{array}$ \\
\hline Constant & $.716(.033)^{* *}$ & $.788(.030)^{* *}$ & $.531(.049)^{* *}$ & $.789(.053)^{* *}$ & $.858(.043)^{* *}$ & $.610(.067)^{* *}$ \\
\hline \multicolumn{7}{|c|}{ Individual-level variables } \\
\hline Ideology (left-right) & $-.034(.005)^{* *}$ & $-.037(.004) * *$ & $-.088(.006)^{* *}$ & $-.032(.005)^{* *}$ & $-.035(.004)^{* *}$ & $-.086(.006)^{* *}$ \\
\hline Self-transcendence & $.134(.010)^{* *}$ & $.149(.010)^{* *}$ & $.134(.013)^{* *}$ & $.129(.010)^{* *}$ & $.139(.010)^{* *}$ & $.127(.013)^{* *}$ \\
\hline $\begin{array}{l}\text { Authoritarian } \\
\text { predispositions } \\
\text { Country-level variables }\end{array}$ & $.066(.010)^{* *}$ & $.055(.010)^{* *}$ & $.084(.013)^{* *}$ & $-.047(.055)$ & $-.067(.058)$ & $-.052(.072)$ \\
\hline $\begin{array}{l}\text { Post-communist } \\
\text { country }\end{array}$ & $.033(.023)$ & $.029(.021)$ & $.010(.034)$ & $.050(.020)^{* *}$ & $.026(.021)$ & $.014(.034)$ \\
\hline Inflation (CPI) & $.000(.000)$ & $-.000(.000)$ & $.000(.000)$ & $-.000(.000)$ & $-.001(.000)^{*}$ & $-.000(.000)$ \\
\hline \multicolumn{7}{|l|}{ Cross-level interactions } \\
\hline $\begin{array}{l}\text { Inflation } \mathrm{x} \\
\text { Authoritarian } \\
\text { predispositions } \\
\text { Random effect paramete }\end{array}$ & $r s$ & - & - & $.001(.000)^{* *}$ & $.001(.000)^{* *}$ & $.001(.000)^{* *}$ \\
\hline Constant & $.046(.006) * *$ & $.042(.006) * *$ & $.069(.010)^{* *}$ & $.073(.014)^{* *}$ & $.078(.015)^{* *}$ & $.095(.018)^{* *}$ \\
\hline Individual level & $.159(.001)^{* *}$ & $.156(.001)^{* *}$ & $.205(.001)^{* *}$ & $.075(.012)^{* *}$ & $.057(.010)^{* *}$ & $.093(.014)^{* *}$ \\
\hline$-2 \times$ Log Likelihood & -24427.58 & -25565.34 & -9559.14 & -24493.14 & -25637.38 & -9621.67 \\
\hline N. Level-1 / N. Level 2 & $29126 / 26$ & $29126 / 26$ & $29036 / 26$ & $29126 / 26$ & $29126 / 26$ & $29036 / 26$ \\
\hline
\end{tabular}

Models include all demographic controls (age, gender, levels of education, income, labor market and social class variables, union membership), as well as religiosity and religious attendance. Entries are non-standardized coefficients with standard errors in parentheses. $* p<0.1$, $* * p<0.05(2$-tailed).

Note that Ukraine, which turned out to be an outlier in terms of level of inflation in 2008, is excluded from the models. 